\title{
WITOLD HUREWICZ, IN MEMORIAM
}

\section{SOLOMON LEFSCHETZ}

Last September sixth was a black day for mathematics. For on that day there disappeared, as a consequence of an accidental fall from a pyramid in Uxmal, Yucatan, Witold Hurewicz, one of the most capable and lovable mathematicians to be found anywhere. He had just attended the International Symposium on Algebraic Topology which took place during August at the National University of Mexico and had been the starting lecturer and one of the most active participants. He had come to Mexico several weeks before the meeting and had at once fallen in love with the country and its people. As a consequence he established from the very first a warm relationship between himself and the Mexican mathematicians. His death caused among all of us there a profound feeling of loss, as if a close relative had gone, and for days one could speak of nothing else.

Witold Hurewicz was born on June 29, 1904, in Lodz, Russian Poland, received his early education there, and his doctorate in Vienna in 1926. He was a Rockefeller Fellow in 1927-1928 in Amsterdam, privaat docent there till 1936 when he came to this country. The Institute for Advanced Study, the University of North Carolina, Radiation Laboratory and Massachusetts Institute of Technology (since 1945) followed in succession.

Mathematically Hurewicz will best be remembered for his important contributions to dimension, and above all as the founder of homotopy group theory. Suffice it to say that the investigation of these groups dominates present day topology.

Still very young, Hurewicz attacked dimension theory, on which he wrote together with Henry Wallman the book Dimension theory [39]. ${ }^{1}$ We come to this book later. The Menger-Urysohn theory, still of recent creation was then in full bloom, and Menger was preparing his book on the subject. One of the principal contributions of Hurewicz was the extension of the proofs of the main theorems to separable metric spaces [ 2 to 10 ] which required a different technique from the basically euclidean one of Menger and Urysohn. Some other noteworthy results obtained by him on dimension are:

(a) $A$ separable metric $n$-space (=n dimensional space) may be topologically imbedded in a compact metric n-space [7].

${ }^{1}$ Square brackers refer to the bibliography at the end. 
(b) Every compact metric $n$-space $Y$ is the map of a compact metric zero-space $X$ in such a manner that no point of $Y$ has more than $n+1$ antecedents, where $n$ cannot be lowered, and conversely where this holds $\operatorname{dim} Y=n$. In particular one may choose for $X$ a linear set containing no interval [6].

(c) Perhaps his best dimension result is his proof and extension of the imbedding theorem of compact spaces of dimension $\leqq n$ in Euclidean $E_{2 n+1}$ which reads: $A$ compact metric $n$-space $X$ may be mapped into $E_{n+m}(m=1,2, \cdots)$, so that the points which are images of $k$ points of $X$ make up a set of dimension $\leqq n-(k-1) m[26]$.

This proposition may also be generalized as follows: Any mapping $f: X \rightarrow E_{n+m}$ may be arbitrarily approximated by one behaving as stated. Special case: $X$ may be mapped topologically into $E_{2 n+1}$. Earlier proofs of this last theorem existed. The wholly original proof of the main theorem by Hurewicz rests upon the utilization of the space $E_{n+m}^{X}$ of mappings of $X \rightarrow E_{n+m}$, as defined by Fréchet and the proof that the mappings of the desired type are dense in $E_{n+m}^{X}$.

A more special but interesting dimensional result is: [10].

(d) Hilbert space is not a countable union of finite dimensional spaces

Recall R. L. Moore's noteworthy proposition: a decomposition of the two-sphere $S^{2}$ in upper semi-continuous continua which do not disconnect $S^{2}$ is topologically an $S^{2}$. Hurewicz showed [17] that for $S^{8}$ no such result holds and one may thus obtain topologically any compact metric space. This shows that $\mathrm{R}$. L. Moore's results describe a very special property of $S^{2}$.

Another investigation of Hurewicz marked his entrance into algebraic topology. The undersigned had introduced so called $L C^{n}$ spaces: compact metric spaces locally connected in terms of images of $p$ spheres for every $p \leqq n$. One may introduce $H L C^{n}$ spaces with images of $p$-spheres replaced by integral $p$-cycles and contractibility to a point by $\sim 0$ in the sense of Vietoris. Hurewicz proved this very unexpected property: N.a.s.c. for $X$ as above to be $L C^{n}$ is $H L C^{n}$ plus local contractibility of closed paths [33]. An analogous condition will appear in connection with homotopy groups.

We come now to the four celebrated 1935 Notes on the homotopy groups, of the Amsterdam Proceedings $[29 ; 30 ; 34 ; 35]$. The attack is by means of the function spaces $X^{Y}$. Let $Y$ be a separable metric space which is connected and locally contractible in the sense of Borsuk. Let $S^{p}$ denote the $p$-sphere. Let $x_{0}$ be a fixed point of $S^{n-1}$, $n \geqq 1$, and $y_{0}$ a fixed point of $Y$. Let $N$ be the subset of $Y^{s^{n-1}}$ consisting of the mappings $F$ such that $F x_{0}=y_{0}$. The group of the paths of $N$ 
is the same for all components of $M$. It is by definition the $n$th homotopy group $\pi_{n}(Y)$ of $Y$. For $n=1$ it is the group of the paths of $Y$, and hence generally noncommutative but for $n>1$ the groups are always commutative. Hurewicz proved the following two noteworthy propositions:

I. When the first $n-1$ ( $n \geqq 2)$ homotopy groups of the space $Y$ (same as before) are zero then the nth $\pi_{n}(Y)$ is isomorphic with $H_{n}(Y)$, the nth integral homology group of $Y$.

II. N.a.s.c. for a finite connected polyhedron $\Pi$ to be contractible to $a$ point is $\pi_{1}(\Pi)=1$ and $H_{n}(\Pi)=0$ for every $n>1$.

For many years only a few homotopy groups were computed successfully. In the last five years however great progress has been made and homotopy groups have at last become computable mainly through the efforts of J.-P. Serre, Eilenberg and MacLane, Henri Cartan, and John Moore.

Many other noteworthy results are found in the four Amsterdam Proceedings Notes but we cannot go into them here. We may mention however the fundamental concept of homotopy type introduced by Hurewicz in the last note: Two spaces $X, Y$ are said to be of the same homotopy type whenever there exist mappings $f: X \rightarrow Y$ and $g: Y \rightarrow X$ such that $g f$ and $f g$ are deformations in $X$ and $Y$. This concept gives rise to an equivalence and hence to equivalence classes. This is the best known approximation to homeomorphism, and comparison according to homotopy type is now standard in topology. Identity of homotopy type implies the isomorphism of the homology and homotopy groups.

At a later date (1941) and in a very short abstract of this Bulletin [40] Hurewicz introduced the concept of exact sequence whose mushroom like expansion in recent topology is well known. The idea rests upon a collection of groups $G_{n}$ and homeomorphism $\phi_{n}$ such that

$$
\cdots \rightarrow G_{n+2} \stackrel{\phi_{n+1}}{\longrightarrow} G_{n+1} \stackrel{\phi_{n}}{\rightarrow} G_{n} \rightarrow \cdots
$$

and so that the kernel of $\phi_{n}$ is $\phi_{n+1} G_{n+2}$. This was applied by Hurewicz to homology groups and he drew important consequences from the scheme.

Still another noteworthy concept dealt with by Hurewicz is that of fibre space. In a Note [38] written in collaboration with Steenrod there was introduced the concept of the covering homotopy, its existence was established in fibre spaces, the power of the method was made clear. He returned to it very recently [45] to build fibre spaces on a very different basis. In another recent Note [46] written in col- 
laboration with Fadell there was established the first fundamental advance beyond the theorem of Leray (1948) about the structure of spectral sequences of fibre spaces.

Hurewicz made a number of excursions into analysis, principally real variables. A contribution of a different nature was his extension of G. D. Birkhoff's ergodic theorem to spaces without invariant measure [42].

During World War II Hurewicz gave evidence of surprising versatility in distinguished work which he did for the Radiation Laboratory. This led among other things to his writing a chapter in the Servo Mechanisms series issued by the Massachusetts Institute of Technology.

The scientific activity of Hurewicz extended far beyond his written papers important as these may be. One way that it manifested itself is through his direct contact with all younger men about him. $\mathrm{He}$ was ready at all times to listen carefully to one's tale and to make all manner of suggestions, and freely discussed his and anybody else's latest ideas. One of his major sources of influence was exerted through his books. Dimension theory [39] already mentioned is certainly the definitive work on the subject. One does not readily understand how so much first rate information could find place in so few pages. We must also mention his excellent lectures on differential equations [41] which has appeared in mimeographed form and has attracted highly favorable attention.

On the human side Witold Hurewicz was an equally exceptional personality. A man of the widest culture, a first rate and careful linguist, one could truly apply to him nihil homini a me alienum puto. Tales were also told of his forgetfulness-which made him all the more charming. Altogether we shall not soon see his equal.

\section{BIBLIOGRAPHY}

1. Über eine Verallgemeinerung des Borelschen Theorems, Math. Zeit. vol. 24 (1925) pp. 401-421.

2. Über schnitte von Punktmengen, Proc. Akad. van Wetenschappen vol. 29 (1926) pp. 163-165.

3. Stetige bilder von Punktmengen. I, Ibid. (1926) pp. 1014-1017.

4. Grundiss der Mengerschen Dimensionstheorie, Math. Ann. vol. 98 (1927) pp. 64-88.

5. Normalbereiche und Dimensionstheorie, Math. Ann. vol. 96 (1927) pp. 736-764.

6. Stetige bilder von Punktmengen. II, Proc. Akad. van Wetenschappen vol. 30 (1927) pp. 159-165.

7. Verhalten separabler Räume zu kompakten Räumen, Ibid. (1927) pp. 425-430.

8. Über Folgen stetiger Funktionen, Fund. Math. vol. 9 (1927) pp. 193-204. 
9. Relativ perfekte Teile von Punktmengen und Mengen, Fund. Math. vol. 12 (1928) pp. 78-109.

10. Über unendlich-dimensionale Punktmengen, Proc. Akad. van Wetenschappen vol. 31 (1928) pp. 916-922.

11. Dimension und Zusammenhangsstufe, (with K. Menger), Math. Ann. vol. 100 (1928) pp. 618-633.

12. Über ein topologisches Theorem, Math. Ann. vol. 101 (1929) pp. 210-218.

13. Über der sogenannter Produktsatz der Dimensionstheorie, Math. Ann. vol. 102 (1929) pp. 305-312.

14. Zu einer Arbeit von O. Schreier, Abh. Math. Sem. Hansischen Univ. vol. 8 (1930) pp. 307-314.

15. Ein Theorem der Dimensionstheorie, Ann. of Math. vol. 31 (1930) pp. 176-180.

16. Einbettung separabler Räume in gleich dimensional kompakte Räume, Monatshefte für Mathematik vol. 37 (1930) pp. 199-208.

17. Über oberhalb-stetige Zerlegungen von Punktmengen in Kontinua, Fund. Math. vol. 15 (1930) pp. 57-60.

18. Theorie der Analytischen mengen, Fund. Math. vol. 15 (1930) pp. 4-17.

19. Dimensionstheorie und Cartesische Räume, Proc. Akad. van Wetenschappen vol. 34 (1931) pp. 399-400.

20. Une remarque sur l'hypothèse du continu, Fund. Math. vol. 19 (1932) pp. 8-9.

21. Über die henkelfreie Kontinua, Proc. Akad. van Wetenschappen vol. 35 (1932) pp. 1077-1078.

22. Stetige abbildungen topologischer Räume, Proc. International Congress Zurich vol. 2 (1932) p. 203.

23. Über Dimensionserhörende stetige Abbildungen, J. Reine Angew. Math. vol. 169 (1933) pp. 71-78. 162.

24. Über Schnitte in topologischen Räumen, Fund. Math. vol. 20 (1933) pp. 151-

25. Ein Einbettungessatz ïber henkelfreie Kontinua (with B. Knaster), Proc. Akad. van Wetenschappen vol. 36 (1933) pp. 557-560.

26. Über Abbildungen von endlich dimensionalen Räumen auf teilmengen cartesischer Räume, Preuss. Akad. Wiss. Sitzungsber. (1933) pp. 754-768.

27. Über einbettung topologischer Räume in cantorsche Mannigfaltigkeiten, Prace Matematyczno. Fizyczne vol. 40 (1933) pp. 157-161.

28. Satz über stetige Abbildungen, Fund. Math. vol. 23, pp. 54-62.

29. Höher-dimensionale Homotopiegruppen, Proc. Akad. van Wetenschappen vol. 38 (1935) pp. 112-119.

30. Homotopie und Homologiegruppen, Proc. Acad. van Wetenschappen vol. 38 (1935) pp. 521-528.

31. Über Abbildungen topologischer Räume auf die n-dimensionale Sphäre, Fund. Math. vol. 24 (1935) pp. 144-150.

32. Sur la dimension des produits cartesiens, Ann. of Math. vol. 36 (1935) pp. 194197.

33. Homotopie, Homologie und lokaler Zusammenhang, Fund. Math. vol. 25 (1935) pp. 467-485.

34. Klassen und Homologietypen von Abbildungen, Proc. Akad. van wetenschappen vol. 39 (1936) pp. 117-126.

35. Asphärische Raume, Ibid. (1936) pp. 215-224. 
36. Dehnungen, Verkürzungen, Isometrien (with H. Freudenthal), Fund. Math. vol. 26 (1936) pp. 120-122.

37. Ein Einfacher Beweis des Hauptsatzes uber cantorsche Mannigfaltigkeiten, Prace Matematyczno Fizyczne vol. 44 (1937) pp. 289-292.

38. Homotopy relations in fibre spaces (with N. E. Steenrod), Proc. Nat. Acad. Sci. U.S.A. vol. 27 (1941) pp. 60-64.

39. Dimension theory (with H. Wallman), Princeton University Press (Princeton Mathematical Series No. 4), 1941, 165 p.

40. On duality theorems, Bull. Amer. Math. Soc. Abstract 47-7-329.

41. Ordinary differential equations in the real domain with emphasis on geometric methods, 129 mimeographed leaves, Brown University Lectures, 1943.

42. Ergodic theorem without invariant measure, Ann. of Math. vol. 45 (1944) pp. 192-206.

43. Continuous connectivity groups in terms of limit groups, (with J. Dugundji and C. H. Dowker) Ann. of Math. (2) vol. 49 (1948) pp. 391-406.

44. Homotopy and homology, Proceedings of the International Congress of Mathematicians, Cambridge, 1950, vol. 2, American Mathematical Society, 1952, pp. 344349.

45. On the concept of fiber space, Proc. Nat. Acad. Sci. U.S.A. vol. 41 (1955) pp. 956-961.

46. On the spectral sequence of a fiber space, (with E. Fadell) Proc. Nat. Acad. Sci. vol. 41 (1955) pp. 961-964.

47. Contributed Chapter 5, Filters and servosystems with pulsed data, pp. 231-261, in James, Nichols and Phillips Theory of servomechanism, Massachusetts Institute of Technology, Radiation Laboratory Series, vol. 25, New York, McGraw-Hill, 1947.

48. Stability of mechanical systems (co-author H. Greenberg), N. D. R. C. Report, 1944 (to appear in the Quarterly of Applied Mathematics).

49. Four reports on servomechanisms for the Massachusetts Institute of Technology Radiation Laboratory. 